\title{
A Study on the Safety of Liver Biopsy Inpatients with Von Willebrand's Disease
}

\author{
Patrick P. Basu',2, Niraj J. Shah ${ }^{3}$, Mark M. Aloysius', K. Rayapudi'2, Robert Brown² \\ ${ }^{1}$ Division of Digestive and Liver Diseases and Center for Liver Disease and Transplantation, Columbia University \\ Medical Center, New York, USA \\ ${ }^{2}$ King's County Hospital Medical Center, New York, USA \\ ${ }^{3}$ Liver Transplant Center, University of North Carolina School of Medicine, Carolinas Medical Center, Charlotte, \\ USA \\ ${ }^{4}$ James J Peters VA Medical Center at Icahn School of Medicine at Mount Sinai, New York, USA \\ Email: nirajjames@gmail.com
}

Received 28 May 2015; accepted 21 September 2015; published 24 September 2015

Copyright @ 2015 by authors and Scientific Research Publishing Inc.

This work is licensed under the Creative Commons Attribution International License (CC BY).

http://creativecommons.org/licenses/by/4.0/

(c) (i) Open Access

\begin{abstract}
Objectives: Liver biopsy remains the gold standard for diagnosis of chronic liver diseases. Outpatient percutaneous biopsy is generally safe with a mortality rate of $0.17 \%$ and hospitalization rate for bleeding of 3\%. Von Willebrand disease (vWD) syndrome is the most common inherited hematological disorder with a prevalence of $1 \%-3 \%$ globally. We sought to study whether vWD increases the risk of bleeding for liver biopsies. Methods: All patients $(n=120)$ who underwent outpatient percutaneous liver biopsies from 1997 to 2007 were analyzed. Demographics, PT/INR, platelet count, $\mathbf{v W}$ antigen and ristocetin induced platelet aggregation were studied. Results: No vWD patients had major bleeding that required transfusion, hospitalization or surgery but 9 (75\%) had minor local bleeding and all had ecchymosis, which resolved spontaneously within 24 hours. Conclusions: Patients with vW factor deficiency can undergo percutaneous liver biopsy without major bleeding. Minor bleeding may occur at a slightly higher rate. vWD is not a contraindication to percutaneous liver biopsy.
\end{abstract}

\section{Keywords}

Liver Biopsy, vW Disease, Safety, Complications

\section{Introduction}

Direct visual documentation of liver disease in its entirety, from aberrant architecture tocytopathology, made

How to cite this paper: Basu, P.P., Shah, N.J., Aloysius, M.M., Rayapudi, K. and Brown, R. (2015) A Study on the Safety of Liver Biopsy Inpatients with Von Willebrand's Disease. Open Journal of Gastroenterology, 5, 134-138.

http://dx.doi.org/10.4236/ojgas.2015.59022 
possibly through biopsy, is an invaluable tool in the clinical armamentarium of the hepatologist. This modality is currently in ubiquitous use for the diagnosis, staging, prognosis and management of a range of infectious, metabolic, autoimmune conditions as well as peri- and post-transplant surveillance. Although newer non-invasiveliver assessment modalities such as transient elastography and MR elastography are making their debut in clinical practice, such novelties are unlikely to replace completely liver biopsy as the gold standard, in the foreseeable future [1]. This invasive procedure is still the mainstay along with its associated hazards, affecting morbidity \& mortality. Performance of outpatient percutaneous liver biopsies is drifting away from clinicians towards interventional radiologists for enhanced safety and reduced complications.

Transjugular liver biopsy as compared with percutaneous liver biopsy (PCLB) in an outpatient setting is by far a safer approach in patients with coagulopathies [2]-[4]. Von Willebrand's disease (vWD) is the most common inherited bleeding disorder, affecting 1 - 3 percent of the global population [5]. There are no data published to date, on the safety of PCLB in patients with vWD.

The objective of our study was to evaluate the safety of PCLB in vWD. We performed a retrospective analysis of PCLBs for hemorrhagic complications (local hematoma, intraabdominal hemorrhage, hemorrhagic shock requiring hospitalization, blood transfusion requirements and surgical intervention). Outpatient PCLBs are generally regarded safe with a mortality rate of $0.17 \%$ and hospitalization rate for bleeding of $3 \%$ [6] [7]. However, there is paucity of published evidence on the risk of hemorrhage and the spectrum of hemorrhagic complications in patients with different types of vWD undergoing PCLB.

\section{Objectives}

The objectives of our study were to determine the prevalence of vWD in patients undergoing liver biopsy as well as the safety of liver biopsy in these patients who had vWD.

\section{Methods}

A retrospective study of patients $(n=120)$ who underwent PCLB in an outpatient setting, as part of a community-based practice from 1997 to 2007, was performed following appropriate institutional board review and approval.

The following medications were withheld for at least 5 days pre-PCBL: anti-platelet drugs (ASA, clopidogrel or NSAIDs) or anti-coagulants (warfarin, unfractionated heparin, LMWH or Xa inhibitors) and subsequently resumed 48 hours post-PCBL when it was deemed clinically safe.

Specific patient populations known to confound the study results were excluded, such as those with:

- Prior known coagulation diathesis (Hemophilia, factor VIII deficiencies)

- Familial history of significant bleeding diathesis

- AV malformations

- Collagen vascular diseases

- Congestive heart failure

- Chronic kidney disease or those on dialysis

A single clinician used a uniform standard technique to carry out the PCBLs [8]. Patients were placed in supine position semi-reclined at 30 degrees and sonography was used to locate the optimal biopsy site [9]. Using an aseptic technique the skin, underlying intercostal spaces as well as the liver capsule were infiltrated with $2 \%$ lignocaine. PCBL was performed using a spring-loaded Tru-Cut liver biopsy needle (Max-Core, BARD ${ }^{\circledR}$ ) which was entered in the mid-axillary line, through $7^{\text {th }}$ or the $8^{\text {th }}$ intercostal space. No more than 3 passes were made, each lasting less than 1 sec through the liver parenchyma, with a cooperative patient holding breath in full expiration.

Post-PCBL, patients were instructed to turn over in a right lateral position for 2 hours and monitored for adverse events.

Following discharge from hospital, all patients included in the study returned to be tested for vWD and subtypes.

\section{Results}

Of the 120 patients who underwent PCBL, 12 (10\%) were found to have vWD, of which 6 patients had type I 
vWD (low levels of vW factor levels) and 6 patients had type II vWD (qualitative defect in vW factor), but none had type III. The prevalence of vWD in our cohort of patients was much higher $(10 \%)$ than the general population (3\%), with a similar distribution between type I and II (Table 1).

There was no major bleeding (requiring transfusion) but 9/12 patients in the vW disease group experienced minor bleeding which settled with pressure. All vW patients also experienced transient post procedural pain lasting $<24$ hours in addition to biopsy site ecchymosis (Table 2).

\section{Discussion}

PCLB is generally regarded as a safe diagnostic modality. Complications of liver biopsy are extremely rare but potentially hazardous [10]. The majority of complications (60\%) occur within two hours, and 96\% occur within 24 hours following the procedure [11] [12]. Less than 3\% of patients following the procedure require inpatient carerelated to adverse event [7] [13]. A third of patients are known to experience significant pain during the procedure itself but clinically significant bleeding following the liver biopsy occurs only in $1 \%-2 \%$, usually apparent within 4 hours post-procedure [6]. Intra-peritoneal hemorrhage is the most disastrousform of bleeding requiring expeditious surgery, others such as intra-parenchymal \& biliary, which are self contained by surrounding tissue usually amenable to angiographic embolization [14]-[16]. Unfortunately, fatalities have occurred from uncontained and missed intra-peritoneal hemorrhage in up to $0.01 \%-0.3 \%$ of patients post-PCBL [6] [17]-[19].

vWD has traditionally been regarded as a general risk factor for bleeding during invasive procedures [20]. Liver biopsies have been performed safely in patient populations with coagulation defects such as thrombocytopenia and hemophilia following clotting factor replacements or substitutes [21]. However, there is paucity of

\section{Table 1. Patient demographics, diagnosis, liver disease severity (MELD), vW disease type and RIPA.}

\begin{tabular}{cccccccc}
\hline $\begin{array}{c}\text { Patient } \\
\text { Number }\end{array}$ & Age & Ethnicity & Sex & Diagnosis & "MELD & $\begin{array}{c}\text { vW Disease Type } \\
\text { (Factor Level \%) }\end{array}$ & $\begin{array}{c}\text { Ristocetin Induced Platelet } \\
\text { Aggregation } \\
\text { (RIPA) }\end{array}$ \\
\hline 1 & 38 & Caucasian & M & Chronic hepatitis B & 6 & I (<45\%) & Hypoactive agglutination \\
2 & 46 & Hispanic & M & PBC & 8 & IIB (Normal) & Hyperactive agglutination \\
3 & 59 & Caucasian & F & Chronic hepatitis C & 8 & I (<45\%) & Hypoactive agglutination \\
4 & 76 & Caucasian & F & Chronic hepatitis C & 6 & IIB (Normal) & Hyperactive agglutination \\
5 & 44 & Caucasian & M & Chronic hepatitis C & 4 & I (<45\%) & Hypoactive agglutination \\
6 & 54 & Caucasian & M & Chronic hepatitis C & 8 & IIN (Normal) & Normal agglutination \\
7 & 67 & Asian & F & PBC & 8 & I (<45\%) & Hypoactive agglutination \\
8 & 50 & Caucasian & M & Chronic hepatitis C & 6 & I (<45\%) & Hypoactive agglutination \\
9 & 43 & Caucasian & F & Chronic hepatitis C & 6 & IIN (Normal) & Normal coagulation \\
10 & 32 & Hispanic & F & Chronic hepatitis B & 8 & IIB (Normal) & Hyperactive coagulation \\
11 & 65 & Caucasian & M & Chronic hepatitis B & 8 & I (<45\%) & Hypoactive coagulation \\
12 & 56 & Caucasian & M & Chronic hepatitis B & 6 & IIN (Normal) & Normal coagulation \\
\hline
\end{tabular}

${ }^{\#}$ MELD—Model for end stage liver disease.

Table 2. Complications in patients with vW disease who underwent liver biopsy.

\begin{tabular}{cc} 
Complication & Patient's $\boldsymbol{n}$ (\%) \\
\hline Pain at the site $<24$ hours & $12(100)$ \\
Biopsy site ecchymosis & $12(100)$ \\
Minor biopsy site bleed & $9(75)$ \\
Major bleeding requiring transfusion & $0(0)$ \\
Hemobilia & $0(0)$ \\
\hline
\end{tabular}


data on the safety of PCLB in vWD (most common inherited bleeding disorder in our population [5], the specific extent of bleeding diathesis encountered in different subtypes of the disease during/post-biopsy and any associated morbidity \& mortality, have not been previously described in literature.

\section{Conclusion}

In conclusion, our study has shown that patients with vWD can safely undergo PCBL without major bleeding requiring transfusion or need for DDAVP (desmopressin acetate) or cryoprecipitate. Minor bleeding and ecchymosis at the biopsy site may occur at a higher rate than the general population. We concur with the AGA guidelines that outpatient percutaneous liver biopsy is safe and non-threatening despite concomitant minor inherited bleeding diathesis [22]. We propose a much larger cohort to obtain better statistical validation.

\section{Guarantor of the Article}

Patrick P Basu.

\section{Specific Author Contributions}

All authors contributed equally to design, data collection and drafting of the manuscript and have all approved the final version before submission.

\section{References}

[1] Nguyen, D. and Talwalkar, J.A. (2011) Noninvasive Assessment of Liver Fibrosis. Hepatology, 53, 2107-2110. http://dx.doi.org/10.1002/hep.24401

[2] Shin, J.L., Teitel, J., Swain, M.G., Bain, V.G., Adams, P.C., Croitoru, K., Peltekian, K., Schweiger, F., Simons, M.E., and Heathcote, E.J. (2005) Virology, Immunology Committee of the Association of Hemophilia Clinic Directors of C. A Canadian Multicenter Retrospective Study Evaluating Transjugular Liver Biopsy in Patients with Congenital Bleeding Disorders and Hepatitis C: Is It Safe and Useful? American Journal of Hematology, 78, 85-93. http://dx.doi.org/10.1002/ajh.20263

[3] Kim, K.R., Ko, G.Y., Sung, K.B., Yoon, H.K., Shin, J.H., Song, H.Y., Ryu, J.H., Hwang, S., Lee, S.G. and Yu, E. (2008) Transjugular Liver Biopsy in Patients with Living Donor Liver Transplantation: Comparison with Percutaneous Biopsy. Liver Transplantation, 14, 971-979. http://dx.doi.org/10.1002/lt.21448

[4] DiMichele, D.M., Mirani, G., Wilfredo Canchis, P., Trost, D.W. and Talal, A.H. (2003) Transjugular Liver Biopsy Is Safe and Diagnostic for Patients with Congenital Bleeding Disorders and Hepatitis C Infection. Haemophilia, 9, 613618. http://dx.doi.org/10.1046/j.1365-2516.2003.00801.x

[5] Sadler, J.E., Mannucci, P.M., Berntorp, E., Bochkov, N., Boulyjenkov, V., Ginsburg, D., Meyer, D., Peake, I., Rodeghiero, F. and Srivastava, A. (2000) Impact, Diagnosis and Treatment of von Willebrand Disease. Thrombosis and Haemostasis, 84, 160-174.

[6] Gilmore, I.T., Burroughs, A., Murray-Lyon, I.M., Williams, R., Jenkins, D. and Hopkins, A. (1995) Indications, Methods, and Outcomes of Percutaneous Liver Biopsy in England and Wales: An Audit by the British Society of Gastroenterology and the Royal College of Physicians of London. Gut, 36, 437-441. http://dx.doi.org/10.1136/gut.36.3.437

[7] Janes, C.H. and Lindor, K.D. (1993) Outcome of Patients Hospitalized for Complications after Outpatient Liver Biopsy. Annals of Internal Medicine, 118, 96-98. http://dx.doi.org/10.7326/0003-4819-118-2-199301150-00003

[8] Brown, K.E., Janney, C.G. and Brunt, E.M. (2000) Liver Disease: Diagnosis and Management. Churchill Livingstone, New York, 47-75.

[9] Caturelli, E., Giacobbe, A., Facciorusso, D., Bisceglia, M., Villani, M.R., Siena, D.A., Fusilli, S., Squillante, M.M. and Andriulli, A. (1996) Percutaneous Biopsy in Diffuse Liver Disease: Increasing Diagnostic Yield and Decreasing Complication Rate by Routine Ultrasound Assessment of Puncture Site. American Journal of Gastroenterology, 91, 13181321.

[10] Rustagi, T., Newton, E. and Kar, P. (2010) Percutaneous Liver Biopsy. Tropical Gastroenterology, 31, $199-212$.

[11] Reddy, K. and Schiff, E. (1996) Complications of Liver Biopsy. 2nd Edition, Williams \& Wilkins, Baltimore.

[12] Piccinino, F., Sagnelli, E., Pasquale, G. and Giusti, G. (1986) Complications Following Percutaneous Liver Biopsy. A Multicentre Retrospective Study on 68,276 Biopsies. Journal of Hepatology, 2, 165-173. http://dx.doi.org/10.1016/S0168-8278(86)80075-7

[13] Pasha, T., Gabriel, S., Therneau, T., Dickson, E.R. and Lindor, K.D. (1998) Cost-Effectiveness of Ultrasound-Guided 
Liver Biopsy. Hepatology, 27, 1220-1226.

[14] Seltzer, R.A., Rossiter, S.B., Cooperman, L.R. and Liebowitz, D. (1976) Hemobilia Following Needle Biopsy of the Liver. American Journal of Roentgenology, 127, 1035-1036. http://dx.doi.org/10.2214/ajr.127.6.1035

[15] Raines, D.R., Van Heertum, R.L. and Johnson, L.F. (1974) Intrahepatic Hematoma: A Complication of Percutaneous Liver Biopsy. Gastroenterology, 67, 284-289.

[16] Lichtenstein, D.R., Kim, D. and Chopra, S. (1992) Delayed Massive Hemobilia Following Percutaneous Liver Biopsy: Treatment by Embolotherapy. American Journal of Gastroenterology, 87, 1833-1838.

[17] Strassburg, C.P. and Manns, M.P. (2006) Approaches to Liver Biopsy Techniques-Revisited. Seminars in Liver Disease, 26, 318-327. http://dx.doi.org/10.1055/s-2006-951599

[18] Froehlich, F., Lamy, O., Fried, M. and Gonvers, J.J. (1993) Practice and Complications of Liver Biopsy. Results of a Nationwide Survey in Switzerland. Digestive Diseases and Sciences, 38, 1480-1484. http://dx.doi.org/10.1007/BF01308607

[19] McGill, D.B., Rakela, J., Zinsmeister, A.R. and Ott, B.J. (1990) A 21-Year Experience with Major Hemorrhage after Percutaneous Liver Biopsy. Gastroenterology, 99, 1396-1400.

[20] Terjung, B., Lemnitzer, I., Dumoulin, F.L., Effenberger, W., Brackmann, H.H., Sauerbruch, T. and Spengler, U. (2003) Bleeding Complications after Percutaneous Liver Biopsy. An Analysis of Risk Factors. Digestion, 67, 138-145.

[21] McMahon, C., Pilkington, R., Shea, E.O., Kelleher, D. and Smith, O.P. (2000) Liver Biopsy in Irish Hepatitis C-Infected Patients with Inherited Bleeding Disorders. British Journal of Haematology, 109, 354-359.

[22] Rockey, D.C., Caldwell, S.H., Goodman, Z.D., Nelson, R.C. and Smith, A.D. (2009) American Association for the Study of Liver D. Liver Biopsy. Hepatology, 49, 1017-1044. http://dx.doi.org/10.1002/hep.22742 